Romanuke $V$.

UDC $519.833+519.6$

\title{
ACCEPTABLE-AND-ATTRACTIVE FINITE APPROXIMATION OF CONTINUOUS NONCOOPERATIVE TWO-PERSON GAMES ON A PRODUCT OF SINUSOIDAL STRATEGY FUNCTIONAL SPACES
}

\author{
V. Romanuke \\ O.S. Popov Odessa National Academy of Telecommunications, \\ Kuzneczna str., 1, Odessa, Ukraine, 65029, \\ e-mail:romanukevadimv@gmail.com
}

\begin{abstract}
A noncooperative two-person game is a model of an economic interaction process considered on a short interval. A whole process, which is a stack of a multitude of the short intervals, is modeled as a series of such noncooperative games. The series of the games is required to be solved without delay, so a method of the finite approximation of continuous noncooperative two-person games is presented. The method is based on sampling the functional spaces, which serve as the sets of pure strategies of the players. The pure strategy is a sinusoidal function of time, in which the phase lag is variable. The spaces of the players' pure strategies are sampled uniformly so that the resulting finite game is a bimatrix game whose payoff matrices are square. The approximation procedure starts with not a great number of intervals. Then this number is gradually increased, and new, bigger, bimatrix games are solved until an acceptable solution of the bimatrix game becomes sufficiently close to the same-type solutions at the preceding iterations. The closeness is expressed in terms of the respective functional spaces, in which the player's strategies at the succeeding iterations should be not farther from each other than at the preceding iterations. These requirements are transformed into the relaxed conditions which allow sampling the players' sets of pure strategies: the respective distance polylines are required to be decreasing on average once they are smoothed with respective polynomials of degree 2, where the parabolas must be having positive coefficients at the squared variable. The acceptable solution is not only a situation, but rather a sub-rectangle of situations, associated with just the phase lags, defined by its center, which is the most attractive situation for the players.

Key words: game theory, payoff functional, sinusoidal strategy, continuous game, finite approximation, attractive situation.
\end{abstract}

\section{INTRODUCTION}

Mathematical modeling by the game-theory approach is a powerful method to simulate and predict redistribution of resources under conditions of predominant demands or queries. Continuous noncooperative two-person games model interactions of a pair of subjects (players or persons) possessing continuums of their pure strategies [1, 2]. Such games are typical for economic interaction processes, where the player may use short-term time-varying strategies [3, 4]. Continuous noncooperative two-person games are specific due to that finding and practicing a solution in mixed strategies is almost intractable even for the case when the players act within finite-dimensional Euclidean subspaces $[3,5,6]$. Moreover, a continuous game may have multiple solutions in pure strategies, so the problem of the single solution selection (or the problem of uniqueness) arises. Furthermore, the solution of a game-theory problem can be defined in several ways using various criteria of equilibrium, profitability, payoff symmetry, stability, etc. Thus, even if the solution is unique, it is not guaranteed to be simultaneously profitable and symmetric $[3,6,7]$. Eventually, an exact solution in pure strategies is not always

(C) Romanuke V., 2020 
determinable as a rigorous search of analytic solutions is possible only in special classes $[2,6,8]$. All these issues can be troubleshot by converting continuity into finiteness: finite two-person games (i. e., bimatrix games) are always easily solvable.

\section{Motivation}

When the player's pure strategy is a time-varying function, its set of pure strategies is functional. As of 2020, games defined on functional spaces are studied weakly, indeed. Besides, peculiarities of finite approximation of such games are not studied and reported at all.

As a simplification, the strategy can be a sinusoidal function of time describing a short-term trend of economic activity $[3,4,6,9]$. In more real circumstances, due to that some economic processes have distinct features of seasonality, the strategy has a sinusoidal component [10]. As the strategy is defined on a short time interval, the length of this interval is usually not longer than the sinusoidal component period. So, a noncooperative game is a model of an economic interaction process considered on just that short interval. A whole process, which is a stack of a multitude of the short intervals, is modeled as a series of such noncooperative games.

The series of the games is required to be solved without delay. Then, every single game is needed to be solved fast, without ambiguity in the solution. This can be provided by finite approximation of continuous noncooperative two-person games, wherein the players' sets of pure strategies are sampled. Obviously, the sampling cannot be arbitrary and should be additionally substantiated.

\section{GoAls AND TASKS TO BE FULFilled}

In the case when the set of the player's pure strategies consists of sinusoidal functions, the pure strategy is determined at least by one parameter (coefficient) which varies through some interval. Usually, this parameter is the phase lag. Without losing generality, the amplitudes of the players' sinusoidal functions can be equal. Their periods (frequencies) can be equal as well. Due to above reasons, the goal is to develop a method of finite approximation of continuous noncooperative two-person games whose players' payoff functionals are defined on a product of sinusoidal strategy functional spaces. For achieving the described goal, the three following tasks are to be fulfilled:

1. To formalize a continuous noncooperative two-person game, in which the player's payoff functional is defined on a product of sinusoidal strategy functional spaces. In such a game, the set of the player's pure strategies is a continuum of sinusoidal functions of time. Pure strategies of the players differ only in the phase lag. The payoff functional is integral.

2. To formalize a method of finite approximation. The conditions which allow sampling the players' sets of pure strategies should be explicitly stated.

3. To discuss applicability and significance of the method, wherein the importance of this contribution and an outlook for a further research should be described.

\section{A Continuous noncooperative two-Person Game}

In this game, each of the players uses short-term time-varying sinusoidal strategies determined by the phase lag. The pure strategy is valid on interval $\left[t_{1} ; t_{2}\right]$ by $t_{2}>t_{1}$, so pure strategies of the player belong to a functional space of sinusoidal functions of time: $S\left[t_{1} ; t_{2}\right] \subset \mathbb{L}_{2}\left[t_{1} ; t_{2}\right]$. Denote the phase lag of the first and second players by $\alpha$ and 
Romanuke $V$.

ISSN 2078-5097. Вісн. Львів. ун-ту. Сер. прикл. матем. та інф. 2020. Вип. 28

$\beta$, respectively. The range of the phase lag in the sinusoidal function cannot be greater than $2 \pi$, so

$$
\alpha \in\left[\alpha_{\min } ; \alpha_{\max }\right] \subset[0 ; 2 \pi] \text { by } \alpha_{\max }>\alpha_{\min }
$$

and

$$
\beta \in\left[\beta_{\min } ; \beta_{\max }\right] \subset[0 ; 2 \pi] \text { by } \beta_{\max }>\beta_{\min } .
$$

Thus, the set of pure strategies of the first player is

$$
\begin{gathered}
X=\left\{x(t)=\sin (t+\alpha), t \in\left[t_{1} ; t_{2}\right]: \alpha \in\left[\alpha_{\min } ; \alpha_{\max }\right] \subset[0 ; 2 \pi]\right\} \subset \\
\subset S\left[t_{1} ; t_{2}\right] \subset \mathbb{L}_{2}\left[t_{1} ; t_{2}\right]
\end{gathered}
$$

and the set of pure strategies of the second player is

$$
\begin{gathered}
Y=\left\{y(t)=\sin (t+\beta), t \in\left[t_{1} ; t_{2}\right]: \beta \in\left[\beta_{\min } ; \beta_{\max }\right] \subset[0 ; 2 \pi]\right\} \subset \\
\subset S\left[t_{1} ; t_{2}\right] \subset \mathbb{L}_{2}\left[t_{1} ; t_{2}\right] .
\end{gathered}
$$

The players' payoffs in situation $\{x(t), y(t)\}$ are

$$
K_{x}(x(t), y(t)) \text { and } K_{y}(x(t), y(t)),
$$

respectively. These payoffs are integral functionals:

$$
K_{x}(x(t), y(t))=\int_{t_{1}}^{t_{2}} f(x(t), y(t)) d t
$$

and

$$
K_{y}(x(t), y(t))=\int_{t_{1}}^{t_{2}} g(x(t), y(t)) d t,
$$

where $f(x(t), y(t))$ and $g(x(t), y(t))$ are algebraic continuous functions of $x(t)$ and $y(t)$. Surely, these functions are defined everywhere on $\left[t_{1} ; t_{2}\right]$. Therefore, the continuous noncooperative two-person game

$$
\left\langle\{X, Y\},\left\{K_{x}(x(t), y(t)), K_{y}(x(t), y(t))\right\}\right\rangle
$$

is defined on product

$$
X \times Y \subset S\left[t_{1} ; t_{2}\right] \times S\left[t_{1} ; t_{2}\right] \subset \mathbb{L}_{2}\left[t_{1} ; t_{2}\right] \times \mathbb{L}_{2}\left[t_{1} ; t_{2}\right]
$$

of sinusoidal strategy functional spaces (3) and (4).

\section{ACCEPtable solutions}

Since a series of games (7) on product (8) is to be solved without delay, the only acceptable solutions are equilibrium or/and efficient situations in pure strategies. Such situations are defined similarly to those in games on finite-dimensional Euclidean subspaces $[1,2]$.

Definition 1. In game (7) defined on product (8) by conditions (1)-(6), situation $\left\{x^{*}(t), y^{*}(t)\right\}$ is an equilibrium situation in pure strategies if inequalities

$$
K_{x}\left(x(t), y^{*}(t)\right) \leqslant K_{x}\left(x^{*}(t), y^{*}(t)\right) \forall x(t) \in X
$$


and

$$
K_{y}\left(x^{*}(t), y(t)\right) \leqslant K_{y}\left(x^{*}(t), y^{*}(t)\right) \forall y(t) \in Y
$$

are simultaneously true.

Definition 2. In game (7) defined on product (8) by conditions (1)-(6), situation $\left\{x^{* *}(t), y^{* *}(t)\right\}$ is an efficient situation in pure strategies if both a pair of inequalities

$$
K_{x}\left(x^{* *}(t), y^{* *}(t)\right) \leqslant K_{x}(x(t), y(t)) \text { and } K_{y}\left(x^{* *}(t), y^{* *}(t)\right)<K_{y}(x(t), y(t))
$$

and a pair of inequalities

$$
K_{x}\left(x^{* *}(t), y^{* *}(t)\right)<K_{x}(x(t), y(t)) \text { and } K_{y}\left(x^{* *}(t), y^{* *}(t)\right) \leqslant K_{y}(x(t), y(t))
$$

are impossible for any $x(t) \in X$ and $y(t) \in Y$.

It is well known that the continuous noncooperative two-person game can have the empty set of equilibria in pure strategies [2]. Moreover, an efficient situation can be too asymmetric, when it is profitable for one player and unprofitable for the other player. In such cases, the game does not have an acceptable solution because one of the players cannot accept it, although the pooled payoff (the sum of players' payoffs) is maximal or close to a maximum (in an efficient situation). Then the concepts of $\varepsilon$-equilibrium and $\varepsilon$-efficiency [2,3] can be applied to equilibrate a situation and smooth payoff asymmetries.

Definition 3. In game (7) defined on product (8) by conditions (1)-(6), situation $\left\{x^{*(\varepsilon)}(t), y^{*(\varepsilon)}(t)\right\}$ is an $\varepsilon$-equilibrium situation in pure strategies for some $\varepsilon>0$ if inequalities

$$
K_{x}\left(x(t), y^{*(\varepsilon)}(t)\right) \leqslant K_{x}\left(x^{*(\varepsilon)}(t), y^{*(\varepsilon)}(t)\right)+\varepsilon \forall x(t) \in X
$$

and

$$
K_{y}\left(x^{*(\varepsilon)}(t), y(t)\right) \leqslant K_{y}\left(x^{*(\varepsilon)}(t), y^{*(\varepsilon)}(t)\right)+\varepsilon \forall y(t) \in Y
$$

are simultaneously true.

Definition 4. In game (7) defined on product (8) by conditions (1)-(6), situation $\left\{x^{* *(\varepsilon)}(t), y^{* *(\varepsilon)}(t)\right\}$ is an $\varepsilon$-efficient situation in pure strategies for some $\varepsilon>0$ if both a pair of inequalities

$$
\begin{gathered}
K_{x}\left(x^{* *(\varepsilon)}(t), y^{* *(\varepsilon)}(t)\right)+\varepsilon \leqslant K_{x}(x(t), y(t)) \text { and } \\
K_{y}\left(x^{* *(\varepsilon)}(t), y^{* *(\varepsilon)}(t)\right)+\varepsilon<K_{y}(x(t), y(t))
\end{gathered}
$$

and a pair of inequalities

$$
\begin{gathered}
K_{x}\left(x^{* *(\varepsilon)}(t), y^{* *(\varepsilon)}(t)\right)+\varepsilon<K_{x}(x(t), y(t)) \text { and } \\
K_{y}\left(x^{* *(\varepsilon)}(t), y^{* *(\varepsilon)}(t)\right)+\varepsilon \leqslant K_{y}(x(t), y(t))
\end{gathered}
$$

are impossible for any $x(t) \in X$ and $y(t) \in Y$.

The best case is when a situation is simultaneously equilibrium (by Definition 1 ) and efficient (by Definition 2). If this is impossible, then the most preferable is an efficient situation in which the pooled payoff is maximal. However, if the payoffs are unacceptably asymmetric, then the best consequent is to find such $\varepsilon$ for which a situation is simultaneously equilibrium (by Definition 3) and efficient (by Definition 4). This approach relates to the method of solving games approximately by providing concessions 
Romanuke $V$.

ISSN 2078-5097. Вісн. Львів. ун-ту. Сер. прикл. матем. та інф. 2020. Вип. 28

49

[11]. Eventually, a payoff asymmetry may be smoothed by a compensation from the player whose payoff is unacceptably greater [6]. Hence, the acceptability of the game solution is determined by following properties (sorted in priority descending order):

1. Simultaneous equilibrium (by Definition 1) and efficiency (by Definition 2).

2. Closeness to efficiency (by Definition 4), which is close to equilibrium (by Definition 3$)$.

3. Closeness to efficiency (by Definition 4), if the exact efficient situation (by Definition 2) either does not exist or is too asymmetric.

4. Closeness to equilibrium (by Definition 3), if the exact equilibrium situation (by Definition 1) either does not exist or is unprofitable (for either a player or both players).

In the list above, property \#3 implies that there are no equilibria, and $\varepsilon$-equilibria are either unprofitable or unacceptably asymmetric. Property \#4 implies that every efficient situation is unacceptably asymmetric and $\varepsilon$-efficient situations are unprofitable as well.

\section{The Finite approximation AS A MAPPing into A Bimatrix GAME}

In game (7) on product (8) by conditions (1) - (6), the pure strategy of the player is factually determined by the phase lag. Therefore, this game can be thought of as it is defined, instead of product (8) of sinusoidal strategy functional spaces (3) and (4), on rectangle

$$
\left[\alpha_{\min } ; \alpha_{\max }\right] \times\left[\beta_{\min } ; \beta_{\max }\right] \subset[0 ; 2 \pi] \times[0 ; 2 \pi] \subset \mathbb{R}^{2} .
$$

This rectangle is easily sampled by using a number of equal intervals along each dimension. Denote this number by $N, N \in \mathbb{N} \backslash\{1\}$. Then

$$
A=\left\{\alpha_{\min }+(n-1) \cdot \frac{\alpha_{\max }-\alpha_{\min }}{N}\right\}_{n=1}^{N+1}=\left\{\alpha_{n}\right\}_{n=1}^{N+1} \subset\left[\alpha_{\min } ; \alpha_{\max }\right] \subset[0 ; 2 \pi]
$$

and

$$
B=\left\{\beta_{\min }+(m-1) \cdot \frac{\beta_{\max }-\beta_{\min }}{N}\right\}_{m=1}^{N+1}=\left\{\beta_{m}\right\}_{m=1}^{N+1} \subset\left[\beta_{\min } ; \beta_{\max }\right] \subset[0 ; 2 \pi] .
$$

So, rectangle (13) is mapped into grid $A \times B$. Set (14) leads to a finite set

$$
\begin{gathered}
X_{A}=\left\{x(t)=\sin (t+\alpha), t \in\left[t_{1} ; t_{2}\right]: \alpha \in A \subset\left[\alpha_{\min } ; \alpha_{\max }\right] \subset[0 ; 2 \pi]\right\}= \\
=\left\{x_{n}(t)=\sin \left(t+\alpha_{n}\right)\right\}_{n=1}^{N+1} \subset X \subset S\left[t_{1} ; t_{2}\right] \subset \mathbb{L}_{2}\left[t_{1} ; t_{2}\right]
\end{gathered}
$$

of pure strategies (sinusoidal functions of time) of the first player, where

$$
x_{1}(t)=\sin \left(t+\alpha_{\min }\right), x_{N+1}(t)=\sin \left(t+\alpha_{\max }\right),
$$

and set (15) leads to a finite set

$$
\begin{gathered}
Y_{B}=\left\{y(t)=\sin (t+\beta), t \in\left[t_{1} ; t_{2}\right]: \beta \in B \subset\left[\beta_{\min } ; \beta_{\max }\right] \subset[0 ; 2 \pi]\right\}= \\
=\left\{y_{m}(t)=\sin \left(t+\beta_{m}\right)\right\}_{m=1}^{N+1} \subset Y \subset S\left[t_{1} ; t_{2}\right] \subset \mathbb{L}_{2}\left[t_{1} ; t_{2}\right]
\end{gathered}
$$

of pure strategies (sinusoidal functions of time) of the second player, where

$$
y_{1}(t)=\sin \left(t+\beta_{\min }\right), y_{N+1}(t)=\sin \left(t+\beta_{\max }\right) .
$$


Hence, product (8) of sinusoidal strategy functional spaces (3) and (4) is mapped into product

$$
X_{A} \times Y_{B} \subset X \times Y \subset S\left[t_{1} ; t_{2}\right] \times S\left[t_{1} ; t_{2}\right] \subset \mathbb{L}_{2}\left[t_{1} ; t_{2}\right] \times \mathbb{L}_{2}\left[t_{1} ; t_{2}\right] .
$$

Subsequently, game (7) on product (8) by conditions (1)-(6) is mapped into a bimatrix $(N+1) \times(N+1)$-game

$$
\begin{gathered}
\left\langle\left\{X_{A}, Y_{B}\right\},\left\{K_{x}(x(t), y(t)), K_{y}(x(t), y(t))\right\}\right\rangle \\
\text { by } x(t) \in X_{A} \text { and } y(t) \in Y_{B} .
\end{gathered}
$$

To perform an appropriate approximation via the sampling, number $N$ is selected so that none of $N^{2}$ rectangles

$$
\left[\alpha_{i} ; \alpha_{i+1}\right] \times\left[\beta_{j} ; \beta_{j+1}\right] \text { by } i=\overline{1, N} \text { and } j=\overline{1, N}
$$

would contain significant specificities of payoff functionals (5) and (6). In fact, such specificities are extremals of these functionals.

Theorem 1. In game (7) defined on product (8) by conditions (1) - (6), the player's payoff functional achieves its maximal and minimal values on any closed subset (subrectangle) of rectangle (13).

Proof. Both $f(x(t), y(t))$ and $g(x(t), y(t))$ are algebraic continuous functions of sinusoidal functions $x(t)$ and $y(t)$ defined everywhere on $\left[t_{1} ; t_{2}\right]$. Therefore, both integrals in functionals (5) and (6) achieve some maximal and minimal values on any closed sub-rectangle of rectangle (13).

It is obvious that Theorem 1 is easily expanded on closed rectangles (20) for any number $N$. Thus, Theorem 1 allows controlling extremals of payoff functionals (5) and (6) by the phase lags. Consequently, if inequalities

$$
\begin{gathered}
\max _{\substack{\alpha \in\left[\alpha_{i} ; \alpha_{i+1}\right], \beta \in\left[\beta_{j} ; \beta_{j+1}\right]}} K_{x}(x(t), y(t))-\min _{\substack{\alpha \in\left[\alpha_{i} ; \alpha_{i+1}\right], \beta \in\left[\beta_{j} ; \beta_{j+1}\right]}} K_{x}(x(t), y(t))= \\
=\max _{\substack{\alpha \in\left[\alpha_{i} ; \alpha_{i+1}\right] \\
\beta \in\left[\beta_{j} ; \beta_{j+1}\right]}} \int_{t_{1}}^{t_{2}} f(x(t), y(t)) d t-\min _{\substack{\alpha \in\left[\alpha_{i} ; \alpha_{i+1}\right] \\
\beta \in\left[\beta_{j} ; \beta_{j+1}\right]}} \int_{t_{1}}^{t_{2}} f(x(t), y(t)) d t \leqslant \mu \\
\forall i=\overline{1, N} \text { and } \forall j=\overline{1, N}
\end{gathered}
$$

and

$$
\begin{gathered}
\max _{\substack{\alpha \in\left[\alpha_{i} ; \alpha_{i+1}\right], \beta \in\left[\beta_{j} ; \beta_{j+1}\right]}} K_{y}(x(t), y(t))-\min _{\substack{\alpha \in\left[\alpha_{i} ; \alpha_{i+1}\right] \\
\beta \in\left[\beta_{j} ; \beta_{j+1}\right]}} K_{y}(x(t), y(t))= \\
=\max _{\substack{\alpha \in\left[\alpha_{i} ; \alpha_{i+1}\right] \\
\beta \in\left[\beta_{j} ; \beta_{j+1}\right]}} \int_{t_{1}}^{t_{2}} g(x(t), y(t)) d t-\min _{\substack{\alpha \in\left[\alpha_{i} ; \alpha_{i+1}\right] \\
\beta \in\left[\beta_{j} ; \beta_{j+1}\right]}} \int_{t_{1}}^{t_{2}} g(x(t), y(t)) d t \leqslant \mu \\
\forall i=\overline{1, N} \text { and } \forall j=\overline{1, N}
\end{gathered}
$$

are simultaneously true for some sufficiently small $\mu>0$, then those $\mu$-variations can be ignored. Thus, for the properly selected $N$ and $\mu$, game (7) defined on product (8) by conditions (1) - (6) can be mapped into and approximated by bimatrix game (19). The quality of the approximation can be comprehended by the following assertions. 
Romanuke $V$.

ISSN 2078-5097. Вісн. Львів. ун-ту. Сер. прикл. матем. та інф. 2020. Вип. 28

51

Theorem 2. If $\left\{x^{*}(t), y^{*}(t)\right\}$ is an equilibrium in game (7) defined on product (8) by conditions (1) - (6), where conditions (21) and (22) hold for some $N$ and $\mu$,

$$
\begin{gathered}
x^{*}(t)=\sin \left(t+\alpha^{*}\right) \text { by } \alpha^{*} \in\left[\alpha_{h} ; \alpha_{h+1}\right] \text { and } \\
y^{*}(t)=\sin \left(t+\beta^{*}\right) \text { by } \beta^{*} \in\left[\beta_{k} ; \beta_{k+1}\right] \text { for } h \in\{\overline{1, N}\}, k \in\{\overline{1, N}\},
\end{gathered}
$$

then every situation $\left\{x^{*(\varepsilon)}(t), y^{*(\varepsilon)}(t)\right\}$ for which

$$
\begin{gathered}
x^{*(\varepsilon)}(t)=\sin \left(t+\alpha^{*(\varepsilon)}\right) \text { by } \alpha^{*(\varepsilon)} \in\left[\alpha_{h} ; \alpha_{h+1}\right] \text { and } \\
y^{*(\varepsilon)}(t)=\sin \left(t+\beta^{*(\varepsilon)}\right) \text { by } \beta^{*(\varepsilon)} \in\left[\beta_{k} ; \beta_{k+1}\right] \\
\text { for } h \in\{\overline{1, N}\}, k \in\{\overline{1, N}\}
\end{gathered}
$$

is an $\varepsilon$-equilibrium for some $\varepsilon>0$. As number $N$ is increased, the value of $\varepsilon$ can be made smaller.

Proof. Inasmuch as $f(x(t), y(t))$ and $g(x(t), y(t))$ are algebraic continuous functions of $x(t)$ and $y(t)$ defined everywhere on $\left[t_{1} ; t_{2}\right]$, functionals $(5)$ and (6) are continuous. Therefore, whichever integer $N$ and the corresponding $\mu$ are, the value of $\varepsilon$ always can be chosen such that inequalities (9) and (10) be true for every situation composed of strategies (24) by (23). Owing to the continuity of the functionals, increasing number $N$ allows decreasing the value of $\mu$, which provides $\varepsilon$-equilibria to be closer to the equilibrium composed of strategies $(23)$.

Theorem 3. If $\left\{x^{* *}(t), y^{* *}(t)\right\}$ is an efficient situation in game (7) defined on product (8) by conditions (1) - (6), where conditions (21) and (22) hold for some $N$ and $\mu$,

$$
\begin{gathered}
x^{* *}(t)=\sin \left(t+\alpha^{* *}\right) \text { by } \alpha^{* *} \in\left[\alpha_{h} ; \alpha_{h+1}\right] \text { and } \\
y^{* *}(t)=\sin \left(t+\beta^{* *}\right) \text { by } \beta^{* *} \in\left[\beta_{k} ; \beta_{k+1}\right] \text { for } h \in\{\overline{1, N}\}, k \in\{\overline{1, N}\},
\end{gathered}
$$

then every situation $\left\{x^{* *(\varepsilon)}(t), y^{* *(\varepsilon)}(t)\right\}$ for which

$$
\begin{gathered}
x^{* *(\varepsilon)}(t)=\sin \left(t+\alpha^{* *(\varepsilon)}\right) \text { by } \alpha^{* *(\varepsilon)} \in\left[\alpha_{h} ; \alpha_{h+1}\right] \text { and } \\
y^{* *(\varepsilon)}(t)=\sin \left(t+\beta^{* *(\varepsilon)}\right) \text { by } \beta^{* *(\varepsilon)} \in\left[\beta_{k} ; \beta_{k+1}\right] \\
\text { for } h \in\{\overline{1, N}\}, k \in\{\overline{1, N}\}
\end{gathered}
$$

is an $\varepsilon$-efficient situation for some $\varepsilon>0$. As number $N$ is increased, the value of $\varepsilon$ can be made smaller.

Proof. Owing to the continuity of functionals (5) and (6), whichever integer $N$ and the corresponding $\mu$ are, value $\varepsilon$ always can be chosen such that inequalities (11) and (12) be true for every situation composed of strategies (26) by (25). It is obvious that, owing to the continuity of the functionals, increasing number $N$ allows decreasing the value of $\mu$, which provides $\varepsilon$-efficient situations to be closer to the efficient situation composed of strategies (25).

Hence, starting with some integer $N$, the finite approximation routine is as follows:

1. Build and solve a bimatrix $(N+1) \times(N+1)$-game $(19)$.

2. Find an acceptable solution in this game.

3 . Stop if the acceptable solution (whether it is an equilibrium, efficient, $\varepsilon$-equilibrium, or $\varepsilon$-efficient situation) by the last iteration does not differ much from the acceptable 
solutions (of the same type) by a few preceding iterations; otherwise, go to the next item.

4. Increase integer $N$ by some increment and go to item $\# 1$.

At the very start of the routine, the increment is not necessary to be 1 . Moreover, the number of equal intervals along each dimension can be increased intensely if the difference between the acceptable solutions decreases slowly. The difference can be considered via the functional closeness. Thus, if

$$
\left\{x^{<l>*}(t), y^{<l>*}(t)\right\}=\left\{\sin \left(t+\alpha^{<l>*}\right), \sin \left(t+\beta^{<l>*}\right)\right\} \in X_{A} \times Y_{B} \subset X \times Y
$$

is an acceptable solution at the $l$-th iteration, then the conditions of the sufficient closeness to the solutions at the preceding and succeeding iterations are as follows:

$$
\begin{gathered}
\sqrt{\int_{t_{1}}^{t_{2}}\left(x^{<l-1>*}(t)-x^{<l>*}(t)\right)^{2} d t} \geqslant \sqrt{\int_{t_{1}}^{t_{2}}\left(x^{<l>*}(t)-x^{<l+1>*}(t)\right)^{2} d t} \text { and } \\
\sqrt{\int_{t_{1}}^{t_{2}}\left(y^{<l-1>*}(t)-y^{<l>*}(t)\right)^{2} d t} \geqslant \sqrt{\int_{t_{1}}^{t_{2}}\left(y^{<l>*}(t)-y^{<l+1>*}(t)\right)^{2} d t}
\end{gathered}
$$

and

$$
\begin{gathered}
\max _{t \in\left[t_{1} ; t_{2}\right]}\left|x^{<l-1>*}(t)-x^{<l>*}(t)\right| \geqslant \max _{t \in\left[t_{1} ; t_{2}\right]}\left|x^{<l>*}(t)-x^{<l+1>*}(t)\right| \text { and } \\
\max _{t \in\left[t_{1} ; t_{2}\right]}\left|y^{<l-1>*}(t)-y^{<l>*}(t)\right| \geqslant \max _{t \in\left[t_{1} ; t_{2}\right]}\left|y^{<l>*}(t)-y^{<l+1>*}(t)\right|
\end{gathered}
$$

by $l=2,3,4, \ldots$ So, if inequalities

$$
\begin{aligned}
& \sqrt{\int_{t_{1}}^{t_{2}}\left(\sin \left(t+\alpha^{<l-1>*}\right)-\sin \left(t+\alpha^{<l>*}\right)\right)^{2} d t} \geqslant \\
& \geqslant \sqrt{\int_{t_{1}}^{t_{2}}\left(\sin \left(t+\alpha^{<l>*}\right)-\sin \left(t+\alpha^{<l+1>*}\right)\right)^{2} d t} \text { and } \\
& \sqrt{\int_{t_{1}}^{t_{2}}\left(\sin \left(t+\beta^{<l-1>*}\right)-\sin \left(t+\beta^{<l>*}\right)\right)^{2} d t} \geqslant \\
& \geqslant \sqrt{\int_{t_{1}}^{t_{2}}\left(\sin \left(t+\beta^{<l>*}\right)-\sin \left(t+\beta^{<l+1>*}\right)\right)^{2} d t}
\end{aligned}
$$

and 


$$
\begin{gathered}
\max _{t \in\left[t_{1} ; t_{2}\right]}\left|\sin \left(t+\alpha^{<l-1>*}\right)-\sin \left(t+\alpha^{<l>*}\right)\right| \geqslant \\
\geqslant \max _{t \in\left[t_{1} ; t_{2}\right]}\left|\sin \left(t+\alpha^{<l>*}\right)-\sin \left(t+\alpha^{<l+1>*}\right)\right| \text { and } \\
\max _{t \in\left[t_{1} ; t_{2}\right]}\left|\sin \left(t+\beta^{<l-1>*}\right)-\sin \left(t+\beta^{<l>*}\right)\right| \geqslant \\
\geqslant \max _{t \in\left[t_{1} ; t_{2}\right]}\left|\sin \left(t+\beta^{<l>*}\right)-\sin \left(t+\beta^{<l+1>*}\right)\right|
\end{gathered}
$$

by $l=2,3,4, \ldots$ hold for at least three iterations, the approximation procedure can be stopped. Clearly, the closeness strengthens if inequalities (30) and (31) hold strictly. However, inequalities (30) and (31) may not hold for a wide range of iterations, so it is better to require that polylines

$$
\begin{aligned}
& \lambda_{x}(l)=\sqrt{\int_{t_{1}}^{t_{2}}\left(\sin \left(t+\alpha^{<l>*}\right)-\sin \left(t+\alpha^{<l+1>*}\right)\right)^{2} d t}, \\
& \eta_{x}(l)=\max _{t \in\left[t_{1} ; t_{2}\right]}\left|\sin \left(t+\alpha^{<l>*}\right)-\sin \left(t+\alpha^{<l+1>*}\right)\right|, \\
& \lambda_{y}(l)=\sqrt{\int_{t_{1}}^{t_{2}}\left(\sin \left(t+\beta^{<l>*}\right)-\sin \left(t+\beta^{<l+1>*}\right)\right)^{2} d t}, \\
& \eta_{y}(l)=\max _{t \in\left[t_{1} ; t_{2}\right]}\left|\sin \left(t+\beta^{<l>*}\right)-\sin \left(t+\beta^{<l+1>*}\right)\right|
\end{aligned}
$$

by $l=1,2,3, \ldots$ be decreasing on average. Herein, term "on average" implies that, in the case when inequalities (30) and (31) do not hold, polylines (32)-(35) are smoothed (approximated) with the respective polynomials of degree 2 (the parabolas must be having positive coefficients at the squared variable). These conditions allow sampling the players' sets of pure strategies without missing better situations.

\section{Practical issues of the Finite approximation}

In practice, the finite approximation may bring a great many of possible solutions. To select the best one (which would be acceptable according to the abovementioned list of properties of the game solution acceptability), a good way, apart from operating on $(28)-(35)$, is to visualize all possible solutions through all iterations. Consider an example in which the seasonality develops through time $t \in[1 ; 30]$ (in economics, this is a really short time interval measured in days or weeks). The set of pure strategies of the first player is

$$
\begin{gathered}
X=\{x(t)=\sin (t+\alpha), t \in[1 ; 30]: \alpha \in[0 ; 1.5 \pi]\} \subset \\
\subset S[1 ; 30] \subset \mathbb{L}_{2}[1 ; 30],
\end{gathered}
$$

and the set of pure strategies of the second player is

$$
\begin{gathered}
Y=\{y(t)=\sin (t+\beta), t \in[1 ; 30]: \beta \in[0 ; 1.5 \pi]\} \subset \\
\subset S[1 ; 30] \subset \mathbb{L}_{2}[1 ; 30] .
\end{gathered}
$$

The payoff functionals are 


$$
K_{x}(x(t), y(t))=\int_{1}^{30}(x(t)-2 y(t))^{2} d t
$$

and

$$
K_{y}(x(t), y(t))=\int_{1}^{30}\left(x^{2}(t)+x(t)-x(t) y(t)-y^{2}(t)\right) d t .
$$

Consequently, this game can be thought of as it is defined on rectangle (13):

$$
[0 ; 1.5 \pi] \times[0 ; 1.5 \pi] \subset[0 ; 2 \pi] \times[0 ; 2 \pi] \subset \mathbb{R}^{2} .
$$

The continuity of functionals (38) and (39) is quite clear. Therefore, Theorem 2 and Theorem 3 ensure finding an acceptable solution by relatively fast finite approximation, i.e., mapping the game given by (36) - (40) into a sequence of bimatrix games. The first player's payoff functional (38) shown in Figure 1 resembles the second player's payoff functional (39) shown in Figure 2. Nevertheless, this is just the shape resemblance, and there is no strict symmetry in equilibrium or efficient situations. Figure 3 shows the aggregate of all equilibrium situations (associated with just the phase lags) found by $N=\overline{5,100}$ (96 bimatrix games altogether) along with all the best efficient situations (at which the pooled payoff is maximal). It is seen that there are two bunches of the best efficient situations. One bunch is on the left upper side of the rectangle of situations, where the phase lag of the first player either is 0 or lies between 0.0471 and 0.1473 (Figure 4). The other bunch is on the right lower side of the rectangle of situations, where the phase lag of the first player lies between 3.366 and 3.5343 (Figure 5).

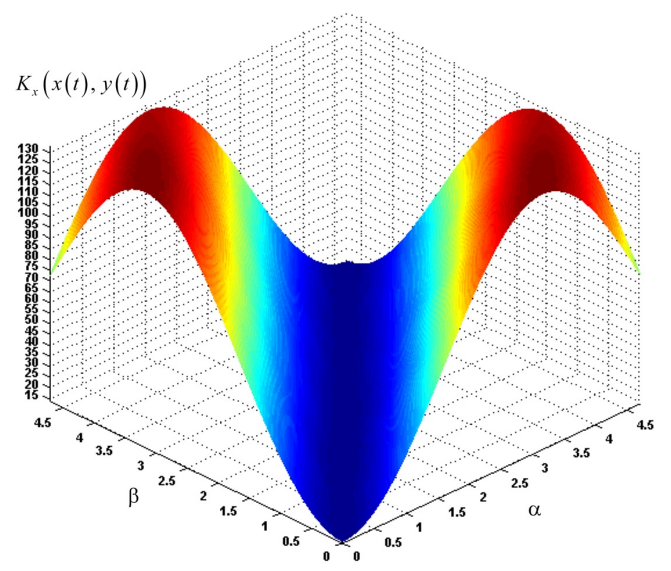

Fig. 1. The first player's payoff functional (38) shown on rectangle (40)

When the approximation procedure is run from $N=5$ to $N=100$, and thus bimatrix $6 \times 6,7 \times 7, \ldots, 100 \times 100,101 \times 101$ games are solved, the best efficient situation bounces between the bunches. Equilibrium situations bounce similarly between the left upper side and the right lower side. Then, obviously, the conditions of the sufficient closeness to the solutions at the preceding and succeeding iterations given by inequalities $(28)-(31)$ are irrelevant for this case. Polylines (32)-(35) cannot be considered as well, unless only 


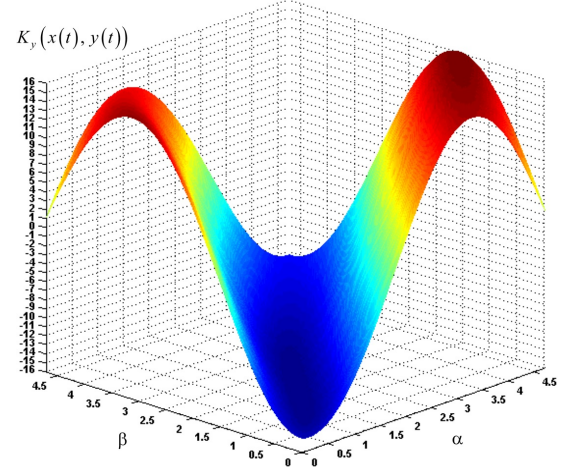

Fig. 2. The second player's payoff functional (39) shown on rectangle (40)

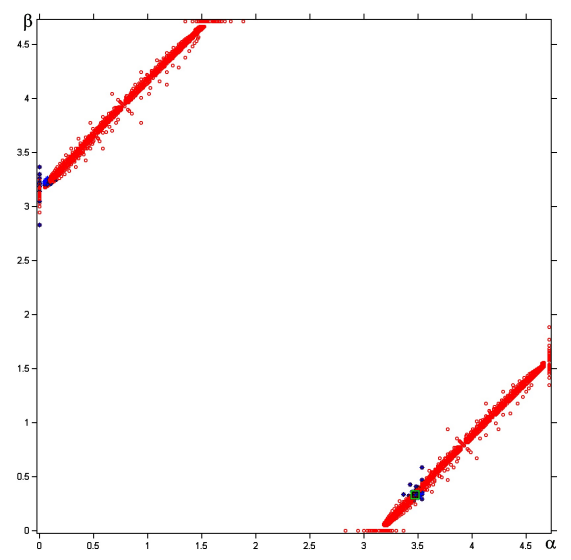

Fig. 3. All equilibria found by $N=\overline{5,100}$ (circles) along with the best efficient situations (*)

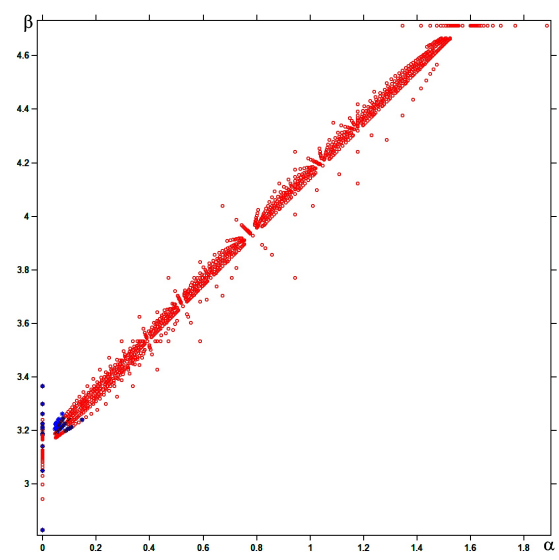

Fig. 4. The zoom-in on the left upper side of the rectangle of situations in Figure 3 


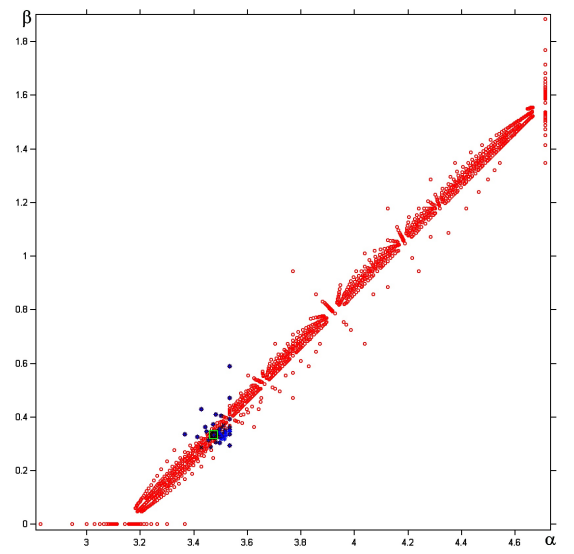

Fig. 5. The zoom-in on the right lower side of the rectangle of situations in Figure 3

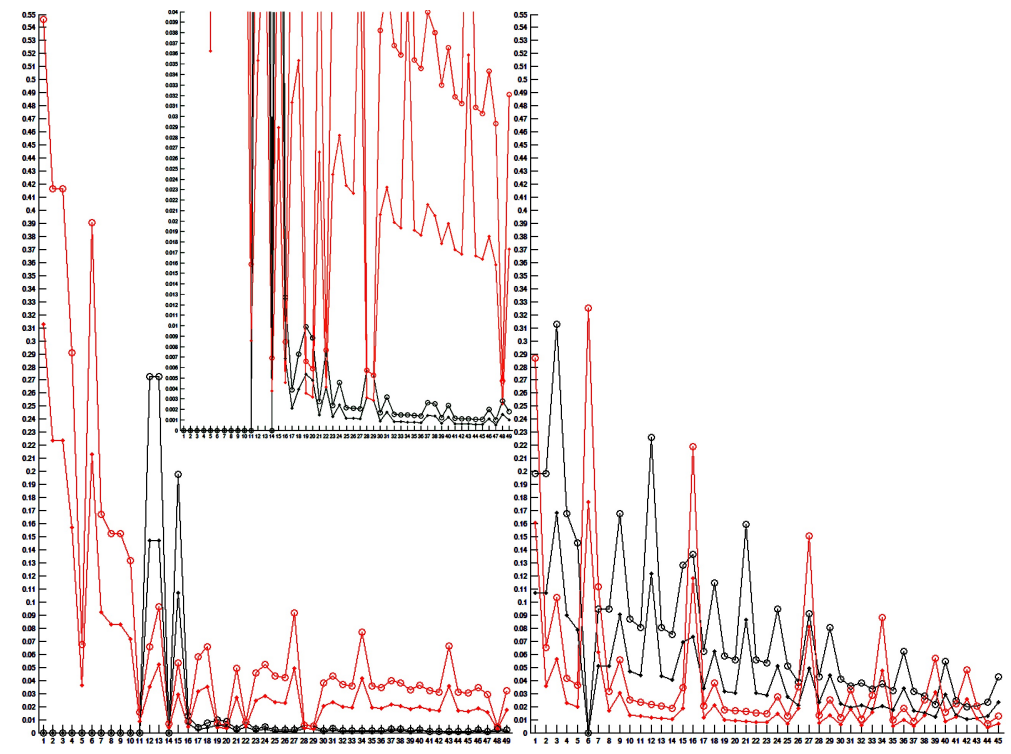

Fig. 6. Polylines (32) - (35) for the left upper side (on the left) and the right lower side (on the right)

one bunch is considered. But which bunch should be preferred? Certainly, each bunch should be considered separately.

First, it is worth to notice that there are 50 best efficient situations in the bunch on the left upper side, whereas the bunch on the right lower side consists of 46 best efficient situations. Polylines (32)-(35) for the 50 best efficient situations in the bunch on the left upper side and polylines (32) - (35) for the 46 best efficient situations in the bunch on the right lower side are shown in Figure 6. As it is easy to see, the polylines in both bunches are decreasing on average. Each side has its peaks in the polylines, though. The left upper side bunch (the left plot in Figure 6) appears to be more attractive for the players to select it by reason of a better density (values along the ordinate axis are less 
Romanuke $V$.

ISSN 2078-5097. Вісн. Львів. ун-ту. Сер. прикл. матем. та інф. 2020. Вип. 28

than those in the right plot, for the right lower side bunch). Meanwhile, the maximal pooled payoff in those best efficient situations seems to be converging to the same point (Figure 7). However, the average pooled payoff in the right lower side bunch is 148.3429 , whereas the average pooled payoff in the left upper side bunch is 148.2832.

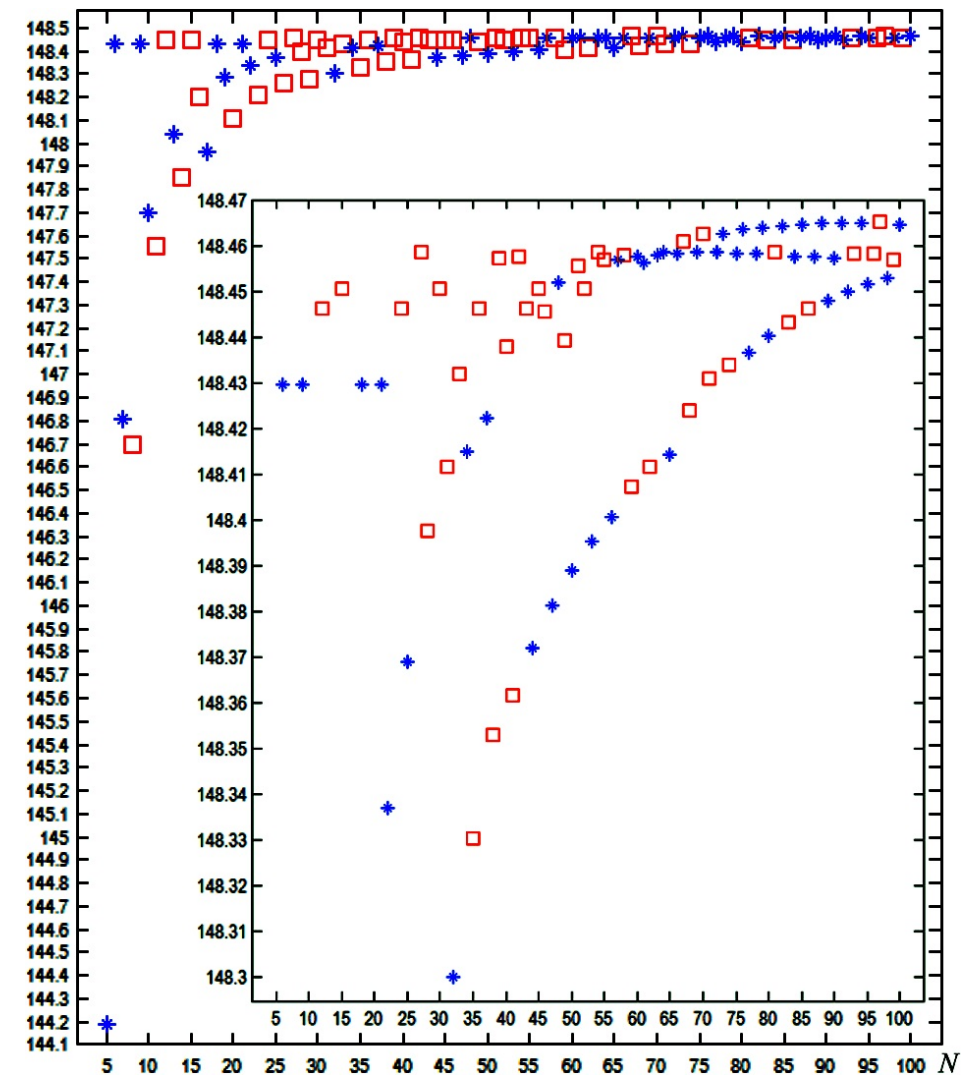

Fig. 7. The maximal pooled payoff in the best efficient situations on the left upper side $(*)$ and on the right lower side (squares)

Although the difference between the average pooled payoffs is only $0.04 \%$, there is another factor which switches the seeming bunch preference from the left upper side to the right lower side. The matter is that the variance of the maximal pooled payoffs on the right lower side is 0.0899 , whereas the variance of the maximal pooled payoffs on the left upper side is 0.4189 , which is $366 \%$ greater (or 4.66 times greater). Consequently, the right lower side bunch of the best efficient situations will attract the players more, and they eventually are expected to select an acceptable solution in the vicinity of the squared point which is seen in Figure 3 and Figure 5. This point,

$$
\left[\begin{array}{ll}
\alpha^{<95>*} & \beta^{<95>*}
\end{array}\right]=\left[\begin{array}{ll}
3.4748 & 0.3332
\end{array}\right]
$$

which could be alternatively called an attractable solution, is the best efficient situation in bimatrix $100 \times 100$-game (at $N=99$, which is the 95 -th iteration; at $N=100$, as it is seen from Figure 7, the best efficient situation bounces back into the left upper side 
bunch). This vicinity is shown in Figure 8 as a zoom-in along with those equilibria which are the closest to the squared point (square-marked situations).

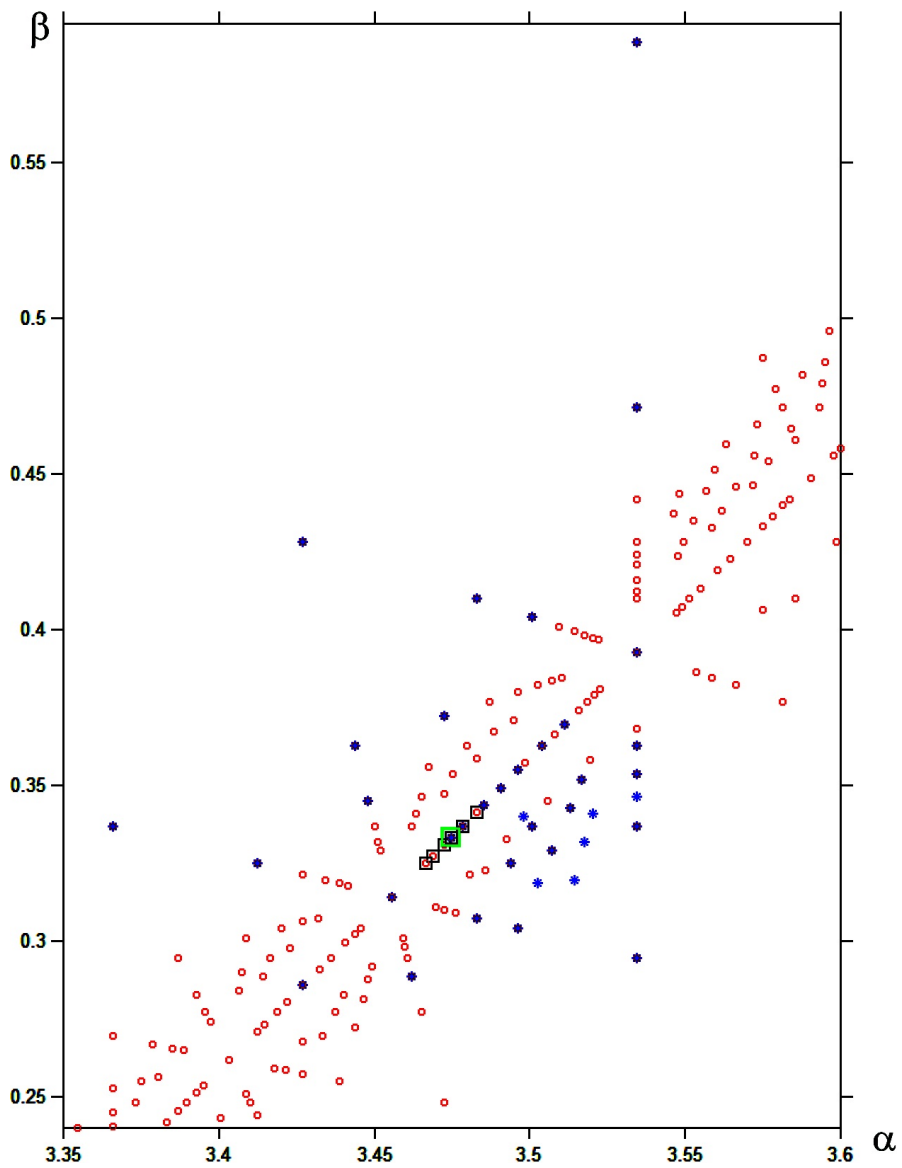

Fig. 8. The zoom-in on the square-marked situations (along with the best efficient situation in bimatrix $100 \times 100$-game) in the right lower side of the rectangle of situations in Figure 5

Point (41) corresponds to the acceptable-and-attractable situation

$$
\left\{x^{<95>*}(t), y^{<95>*}(t)\right\}=\{\sin (t+3.4748), \sin (t+0.3332)\}
$$

which is simultaneously equilibrium and efficient (in the respective bimatrix $100 \times 100$ game). The players receive payoffs

$$
K_{x}\left(x^{<95>*}(t), y^{<95>*}(t)\right)=133.4009
$$

and

$$
K_{y}\left(x^{<95>*}(t), y^{<95>*}(t)\right)=15.0558
$$

in situation (42), where the pooled payoff is 148.4568 (the regular round-off is applied herein). Another point

$$
\left[\begin{array}{ll}
\alpha^{<38>*} & \beta^{<38>*}
\end{array}\right]=\left[\begin{array}{ll}
3.4782 & 0.3366
\end{array}\right]
$$


Romanuke $V$.

is very close to point (41), and it is an equilibrium-and-efficient situation also, where

$$
K_{x}\left(x^{<38>*}(t), y^{<38>*}(t)\right)=133.3958
$$

and

$$
K_{y}\left(x^{<38>*}(t), y^{<38>*}(t)\right)=15.0616,
$$

so the pooled payoff is 148.4574. Although the remaining four square-marked situations (see Figure 8) are not efficient, their payoffs are still close to the payoffs in situation (42): the first player's payoff varies between 133.3883 and 133.4127, and the second player's payoff varies between 15.0419 and 15.0698 (the pooled payoff varies between 148.4546 and 148.458). This confirms that, in the game given by $(36)-(40)$, the (rationally thinking) players will try to "hit" on situation (42) defined by point (41) or on situations defined by points in the vicinity of points (41), (43), and related ones (see square-marked situations in Figure 8). An inaccurate "hit" will not worsen the player's payoff much, and that is the main attractiveness (along with the acceptability) of the square-marked situations in Figure 8.

Therefore, the acceptable solution in the considered example is not just a situation, but rather a sub-rectangle of situations (associated with just the phase lags) defined by its center (the most attractive situation). In this case, the center has been assigned to point (41), although it depends on how many iterations are made. In general, the finite approximation may have practical issues caused by multiplicity of acceptable solutions and solution bounces (instability), which subsequently may lead to new selection problems.

\section{Discussion}

The finite approximation makes game solutions tractable so that they can be easily implemented and practiced. In practice, the tractable finite solution approximating the initial continuous game solutions becomes literally attractable, whereupon it can evolve into an attractive situation. This justifies the applicability of the presented finite approximation method.

Of course, the finite approximation does not remove or solve the single situation selection problem. However, it simplifies not needing operations over continuums (e.g., of equilibria) anymore. The essential drawback may arise in the case when, for instance, there are multiple bunches of equilibria (not like just the two bunches in the aboveconsidered example). The only discharge is to solve new, bigger, bimatrix games to accumulate sufficient statistics of approximate solutions, whereupon to decide on which one attracts the players. Surely, the players are presumed to be rationally thinking ones.

The presented method is quite significant for avoiding too complicated solutions resulting from game continuities and, moreover, functional spaces of pure strategies. Mainly, it concerns modeling economic interaction processes, where the player can use a continuum of short-term time-varying strategies influenced by seasonality. It is a kind of unavoidable simplification, which "deeinstellungizes" the continuous noncooperative two-person game by mapping it into a bimatrix game.

\section{CONCLUSiON}

For solving continuous noncooperative two-person games on a product of sinusoidal strategy functional spaces, a method of their finite approximation is presented, which is 
based on sampling the sinusoidal strategy functional spaces. The sets of the players' pure strategies (i. e., the spaces of pure strategies) are sampled uniformly so that the resulting finite game is a bimatrix game whose payoff matrices are square. The approximation procedure starts with not a great number of intervals along the player's phase lag. Then this number is gradually increased, and new, bigger, bimatrix games are solved until an acceptable solution of the bimatrix game becomes sufficiently close to the same-type solutions at the preceding iterations. The closeness is expressed in terms of the respective functional spaces, in which the player's strategies at the succeeding iterations should be not farther from each other than at the preceding iterations. These requirements are transformed into the relaxed conditions which allow sampling the players' sets of pure strategies: the respective distance polylines are required to be decreasing on average once they are smoothed (approximated) with respective polynomials of degree 2, where the parabolas must be having positive coefficients at the squared variable.

Theoretically, continuous noncooperative games of three and more players within functional spaces are believed to be finitely approximated in the similar manner. However, practical aspects of determining the acceptable-and-attractive solution will have deeper difficulties (there may be more bunches, irregular bounces, slow convergent pooled payoffs, etc.). Nevertheless, the presented game finite approximation has a certain promising impact on modeling economic interaction processes, where players use shortterm time-varying strategies influenced by seasonality.

\section{REFERENCES}

1. Nisan N. Algorithmic Game Theory / N. Nisan, T.Roughgarden, É. Tardos, V.V.Vazirani.- Cambridge, UK: Cambridge University Press, 2007.- 778 p.

2. Vorob'yov N.N. Game theory fundamentals. Noncooperative games / N. N. Vorob'yov.Moscow: Nauka, 1984.-496 p. (In Russian).

3. Vorob'yov N.N. Game theory for economists-cyberneticists / N. N. Vorob'yov.- Moscow: Nauka, 1985. - 272 p. (In Russian).

4. YangJ. Group formation in the spatial public goods game with continuous strategies / J. Yang, Y.-S. Chen, Y.Sun, H.-X. Yang, Y.Liu // Physica A: Statistical Mechanics and its Applications. - 2018. - Iss. 505.- P. 737-743.

5. Romanuke $V . V$. Approximation of unit-hypercubic infinite antagonistic game via dimension-dependent irregular samplings and reshaping the payoffs into flat matrix wherewith to solve the matrix game / V. V. Romanuke // Journal of Information and Organizational Sciences. - 2014. - Vol. 38, No. 2. - P. 125-143.

6. Romanuke $V$. $V$. Ecological-economic balance in fining environmental pollution subjects by a dyadic 3-person game model / V. V. Romanuke //Applied Ecology and Environmental Research. - 2019. - Vol. 17, No. 2.- P. 1451-1474.

7. Harsanyi J. C. A General Theory of Equilibrium Selection in Games / J.C. Harsanyi, R. Selten.- Cambridge Mass.: The MIT Press, 1988. - 396 p.

8. Kontogiannis S. C. Polynomial algorithms for approximating Nash equilibria of bimatrix games / S. C. Kontogiannis, P. N. Panagopoulou, P. G. Spirakis // Theoretical Computer Science. - 2009. - Vol. 410, Iss. 17. - P. 1599-1606.

9. Wang J. Learning continuous and consistent strategy promotes cooperation in prisoner's dilemma game with mixed strategy / J. Wang, R. Wang, F. Yu, Z. Wang, Q. Li // Applied Mathematics and Computation. - 2020.- Vol. 370 - 124887.

10. Hirshleifer D. Mood beta and seasonalities in stock returns / D. Hirshleifer, D. Jiang, Y. M. DiGiovanni // Journal of Financial Economics. - 2020. - Vol. 137, Iss. 1. - P. 272-295. 
Romanuke $V$.

ISSN 2078-5097. Вісн. Львів. ун-ту. Сер. прикл. матем. та інф. 2020. Вип. 28

11. Romanuke $V . V$. Approximate equilibrium situations with possible concessions in finite noncooperative game by sampling irregularly fundamental simplexes as sets of players' mixed strategies / V. V. Romanuke // Journal of Uncertain Systems.- 2016.- Vol.10, No.4.P. 269-281.

Article: received 08.06 .2020

revised 21.09.2020

printing adoption 23.09.2020

\section{ПРИЙНЯТНА ТА ПРИВАБЛИВА СКІНЧЕННА АПРОКСИМАЦІЯ НЕПЕРЕРВНИХ БЕЗКОАЛІЩЙНИХ ІГОР ДВОХ ОСІБ НА ДОБУТКУ ФУНКЦІОНАЛЬНИХ ПРОСТОРІВ СИНУСОЇДНИХ СТРАТЕГІЙ}

\section{В. Романюк}

Одесъка націоналъна академія зв'язку ім. О. С. Попова, вул. Кузнечна, 1, Одеса, Україна, 65029, e-mail:romanukevadimv@gmail.com

Безкоаліційна гра двох осіб є моделлю процесу економічної взаємодії, що розглядається на короткому інтервалі. Увесь процес, який є поєднанням множини цих коротких інтервалів, моделюється як послідовність таких безкоаліційних ігор. Потрібно, щоб ця послідовність ігор розв'язувалася без затримок, тому подається метод скінченної апроксимації неперервних безкоаліційних ігор двох осіб. Цей метод грунтується на дискретизації функціональних просторів, які слугують множинами чистих стратегій гравців. Чиста стратегія $\in$ синусоїдною функцією часу, в якій запізнення за фазою змінне. Простори чистих стратегій гравців дискретизуються рівномірно так, що отримувана скінченна гра є біматричною грою, чиї матриці виграшів квадратні. Процедура апроксимації розпочинається 3 невеликої кількості інтервалів. Далі ця кількість поступово збільшується і розв'язуються нові, більші, біматричні ігри доти, доки прийнятний розв'язок біматричної гри не стане достатньо близьким до розв'язків такого ж типу на попередніх ітераціях. Така близькість виражається у виразах відповідних функціональних просторів, у яких стратегії гравця на наступних ітераціях мають бути не далі одна від одної, ніж на попередніх ітераціях. Ці вимоги перетворюються у послаблені умови, що дають змогу дискретизувати множини чистих стратегій гравців: потрібно, щоб відповідні ламані відстаней були спадними у середньому, як тільки вони згладжуються за допомогою відповідних поліномів другого степеня, де параболи мають додатні коефіцієнти при квадраті змінної. Прийнятний розв'язок не є лише якоюсь однією ситуацією, а, скоріш, деяким під-прямокутником ситуацій, асоційованим тільки з запізненнями за фазою, який визначається своїм центром, що є найбільш привабливою ситуацією для гравців.

Ключові слова: теорія ігор, функціонал виграшів, синусоїдна стратегія, неперервна гра, скінченна апроксимація, приваблива ситуація. 